\title{
Body Mass Index: A Comparison of Male Saudi Students to Americans of the Same Age
}

\author{
Mehdi Ben Brahim ${ }^{1,2}$, Rim Bougatfa ${ }^{3}$, Ossama Abukhaizaran1, Phil Moore1, Won Dae Kim¹ \\ ${ }^{1}$ Department of Physical Education, Health and Recreation, Prince Sultan University, Riyadh, Kingdom of Saudi Arabia \\ ${ }^{2}$ Laboratory of Fonctional Neurophysiology and Pathology, Faculty of Sciences of Tunis, University of Tunis, Tunis, Tunisia \\ ${ }^{3}$ Department of Basic Medical Sciences, College of Medicine, Al Farabi Private College, Riyadh, Kingdom of Saudi Arabia \\ Email: *mehdi.ben-brahim@hotmail.fr
}

How to cite this paper: Brahim, M. B., Bougatfa, R., Abukhaizaran, O., Moore, P., \& Kim, W. D. (2016). Body Mass Index: A Comparison of Male Saudi Students to Americans of the Same Age. Advances in Physical Education, 6, 344-350. http://dx.doi.org/10.4236/ape.2016.64035

Received: August 29, 2016

Accepted: October 29, 2016

Published: November 2, 2016

Copyright $\odot 2016$ by authors and Scientific Research Publishing Inc. This work is licensed under the Creative Commons Attribution International License (CC BY 4.0).

http://creativecommons.org/licenses/by/4.0/

cC) (†) Open Access

\begin{abstract}
Background: Recently obesity has become an epidemic health problem, not only in western countries but also in developing countries. We aim to provide contemporary estimates of the prevalence of obesity in Saudi male university students 18 - 20 years of age. We then compare these estimates to the most recently available estimates observed in American males of the same age. Methods: In this cross-sectional study, we collected anthropometric and physical fitness data on 293 Prince Sultan University (Riyadh, Kingdom of Saudi Arabia) male students aged 18 to 20 years. Obesity was defined as a Body Mass Index (BMI) above the 95th percentile of the Centers for Disease Control (CDC) sex-specific BMI-for-age growth charts for those 18 to 19 years old and as a BMI greater than 30 for those 20 years old. Data on their American counterparts were obtained the national Health and Nutrition. Evaluation survey (NHANES). Results: The mean BMI for the Saudi students was $25.7(\mathrm{SD}=5.99)$ and the mean Waist to Height ratio was $0.498(\mathrm{SD}=0.07)$. The prevalence of Obesity in Saudi students was $24.2 \%, 95 \% \mathrm{CI}=(19.3 \%, 29.0 \%)$ and was not significantly different from the proportion of obese among their American counterparts (estimated to be between 16.6\% and 29.3\%). Discussion: In terms of obesity, Saudi male students were comparable to American males of the same age. Knowing that America is one of the most obese countries in the world, these figures rises some serious concerns about the future health risks of these students and calls for appropriate prevention programs.
\end{abstract}

\section{Keywords}

Prevalence, Obesity, Saudi Students

\section{Introduction}

Recently obesity has become an epidemic health problem, not only in western countries but also in developing countries (Abbasi, Brown, Lamendola, McLaughlin, \& Reaven, 
2002). The rapid growth of the economy has turned Saudi Arabia into a rich country. Prosperity means better education and more sedentary office jobs; it also means more access to fast foods and more adherence to unhealthy eating habits. As a result Saudi Arabia, just like western countries, has now to deal with obesity, one of the burdens of rich countries (Al-Rethaiaa, Fahmy, \& Al-Shwaiyat, 2010; CDC National Center for Health Statistics, 2011).

A few studies provided estimates of the prevalence of obesity in the Saudi population (Al-Nozha et al., 2005; Alsaif et al., 2002, Al-Rukban, 2003; Al-Almaie, 2005). These studies used different definitions of obesity based on Body Mass Index cut-offs and highlighted high percentages of overweight and obese young and adult Saudis. In recent past years, eating habits of young Saudis changed dramatically with the massive presence of American fast food chains in major cities. In rich Saudi Arabia, students have access to internet, mobile technology and social media, which promotes sedentary life. Change in diet (more fast food) and less activity, due to more office jobs and extensive use of technology, are the two major factors contributing to the increase in obesity in the general population and particularly in adolescents. In this paper, we used the Centers for Disease Control (CDC) sex-specific BMI-for-age growth charts from 2000 (Grummer-Strawn et al., 2010) to define obesity. We aimed not only to estimate the prevalence of obesity in young Saudi male students, but we also aimed to answer the question: Are Saudi young male students more likely or less likely to be obese than Americans of the same age? We also compared Saudi male students to their American counterparts in terms of Body Mass Index (BMI), Weight, Height, Waist, and Waist to height ratio (WHR).

\section{Methods}

\subsection{Data Sources}

In this cross-sectional study, we collected anthropometric and physical fitness data on 293 randomly selected male students 18 to 20 years of age during their preparatory years at Prince Sultan University (PSU) in Riyadh, Kingdom of Saudi Arabia. Using a computer random number generator, the sample was selected from students majoring in different fields (humanities, engineering and business). The study Protocol was approved by the Research and Translation Center at Prince Sultan University. All participants signed a written informed consent prior to enrollment in the study.

The national Health and Nutrition Evaluation survey (NHANES) is a survey designed to evaluate the health and nutritional status of the United States population (Freedland et al., 2008). This survey consists of a combination of interviews and physical examinations on a cross-sectional, complex probability sample of the US noninstitutionalized adults and children. Each surveyed person is assigned a numerical weight that measures the number of individuals in the US noninstitutionalized population that are represented by that person. We used anthropometric data on the sub-sample of males 18 to 20 years that attended both interview and physical examination data in the 2011-2012 survey. This subsample consisted on 211 individuals and was representative 
of 7,342,586 American males age 18 - 20 years-subsequently herein referred to as the US sub-population.

\subsection{Measurements}

\section{Anthropometric data}

Anthropometric data (weight, height and waist circumference) on the Prince Sultan University (PSU) students were measured by a trained professional. All anthropometric measurements were taken while the student is in full standing position and wearing light clothing. Body height was taken to the nearest $1 \mathrm{~cm}$ using a stadiometer (Holtain Ltd., Crymych, UK). Weight was measured to the nearest 100 gram using an electronic scale (Seca Instruments Ltd., Hamburg, Germany). Waist circumference was performed at the end of a normal expiration and measured at a level midway between the lowest rib and the crista iliaca superior. Waist to Height Ratio was calculated by dividing the waist by Height. Body mass index was calculated as weight in kilograms divided by height in metres squared.

Obesity

Students aged 18 to 19 years were classified as obese if their BMI was above the 95th percentile of the Centers for Disease Control (CDC) sex-specific BMI-for-age growth charts from 2000 (Grummer-Strawn et al., 2010). Students aged 20 years and older were classified as obese if their BMI was greater than or equal to 30 . The same obesity criteria was used for the US-population.

\subsection{Statistical Methods}

Prevalence of obesity was defined as the number of obese participants divided by the total number of participant. Using a conservative estimate of 0.5 for the prevalence a sample size of 267 was needed to achieve a precision of \pm 0.06 . Prevalence was reported as the number of cases per 100 individuals. Prevalence estimates of obesity in the US Male population 18 - 20 years of age, along with the other anthropometric measures, were obtained using the 2011-2012 National Health and Nutrition Examination Survey. To take into account the complex sampling design of the NHANES survey we used the R package "survey" (James et al., 2004) to derive standard errors of estimates for the US sub-population. Standard errors of the mean differences between the two groups (the PSU students and the US subpopulation) were obtained as the square root of the sum of the variances of estimates. Confidence intervals for the means within the two groups and for the mean differences were obtained as the mean estimates \pm 1.96 times the standard error of the estimates.

\section{Results}

Table 1 shows mean anthropometric measure of PSU students. The mean BMI was $25.7(\mathrm{SD}=5.99)$ and the mean Waist to Height ratio was $0.498(\mathrm{SD}=0.07)$.

There was no significant difference in the prevalence of obesity between PSU students and the American male population of the same age: in PUS students between 19\% 
and 29\% were obese; in the American male population (18 - 20 years of age), between $17 \%$ and $29 \%$ were obese; the difference in the prevalence of obesity between the two groups was estimated between $-6.8 \%$ and $9.3 \%$. Aside from Height-American males were significantly taller than PSU students-we did not observe any significant difference between PSU students and the US male population in terms of Weight, Body Mass Index, Waist circumference and Waist to height ratio (Table 2). Figure 1 compares the proportion of PSU students to the proportion of the US male population (18 - 20 years of age) within each category of the BMI index: all confidence intervals overlapped, showing no significant differences between the two groups. A similar comparison between the two groups within categories of the waist to height ratio is presented in Figure 2. Here again all confidence intervals overlapped and no significant differences between the two groups were observed.

\section{Discussion}

This study provided a direct comparison of a group of Saudi young male students to their American counterparts. We found no significant difference in the prevalence of obesity between the participating Saudi male students and the American male population of the same age. Knowing that the United States is the most obese country in the world, the fact that the prevalence of obesity in participating Saudi students was similar

Table 1. Characteristics of participating Saudi students.

\begin{tabular}{ccc}
\hline Characteristic & Mean & Standard Deviation \\
\hline Age in Years & 19.2 & 0.8 \\
Weight in KGs & 78.2 & 19.5 \\
Height in cm's & 174.1 & 6.3 \\
Waist in cm's & 86.7 & 12.8 \\
Body Mass Index & 25.7 & 6.0 \\
Waist to Height Ratio & 0.498 & 0.071 \\
\hline
\end{tabular}

Table 2. Age and anthropometric measures; means (with 95\% CI's) within and mean differences (with 95\% CI's) between PSU students and their American counterparts.

\begin{tabular}{cccccccc}
\hline & \multicolumn{2}{c}{ PSU Students } & US Population & \multicolumn{2}{c}{ Difference } \\
\hline Characteristic & Mean & $\begin{array}{c}\text { 95\% CI for } \\
\text { the Mean }\end{array}$ & Mean & $\begin{array}{c}\text { 95\% CI for } \\
\text { the Mean }\end{array}$ & Mean & $\begin{array}{c}\text { 95\% CI for } \\
\text { the Mean Difference }\end{array}$ \\
\hline Age (in years) & 19.2 & $(19.119 .3)$ & 19.1 & $(18.919 .2)$ & 0.1 & $(-0.110 .31)$ \\
Weight $(\mathrm{Kg})$ & 78.2 & $(76.080 .4)$ & 79.9 & $(77.382 .7)$ & -1.76 & $(-5.271 .74)$ \\
Height $(\mathrm{cm})$ & 174.1 & $(173.4174 .8)$ & 176.3 & $(175.1177 .5)$ & -2.18 & $(-3.57-0.79)$ \\
Body Mass Index $\left(\mathrm{Kg} / \mathrm{m}^{2}\right)$ & 25.7 & $(25.126 .4)$ & 25.7 & $(24.926 .6)$ & 0.01 & $(-1.101 .11)$ \\
Waist Circumference $(\mathrm{cm})$ & 86.7 & $(85.288 .1)$ & 87.6 & $(85.989 .4)$ & -0.97 & $(-3.271 .33)$ \\
Waist to Height Ratio & 0.498 & $(0.4900 .506)$ & 0.498 & $(0.4870 .510)$ & -0.001 & $(-0.0140 .013)$ \\
\hline
\end{tabular}




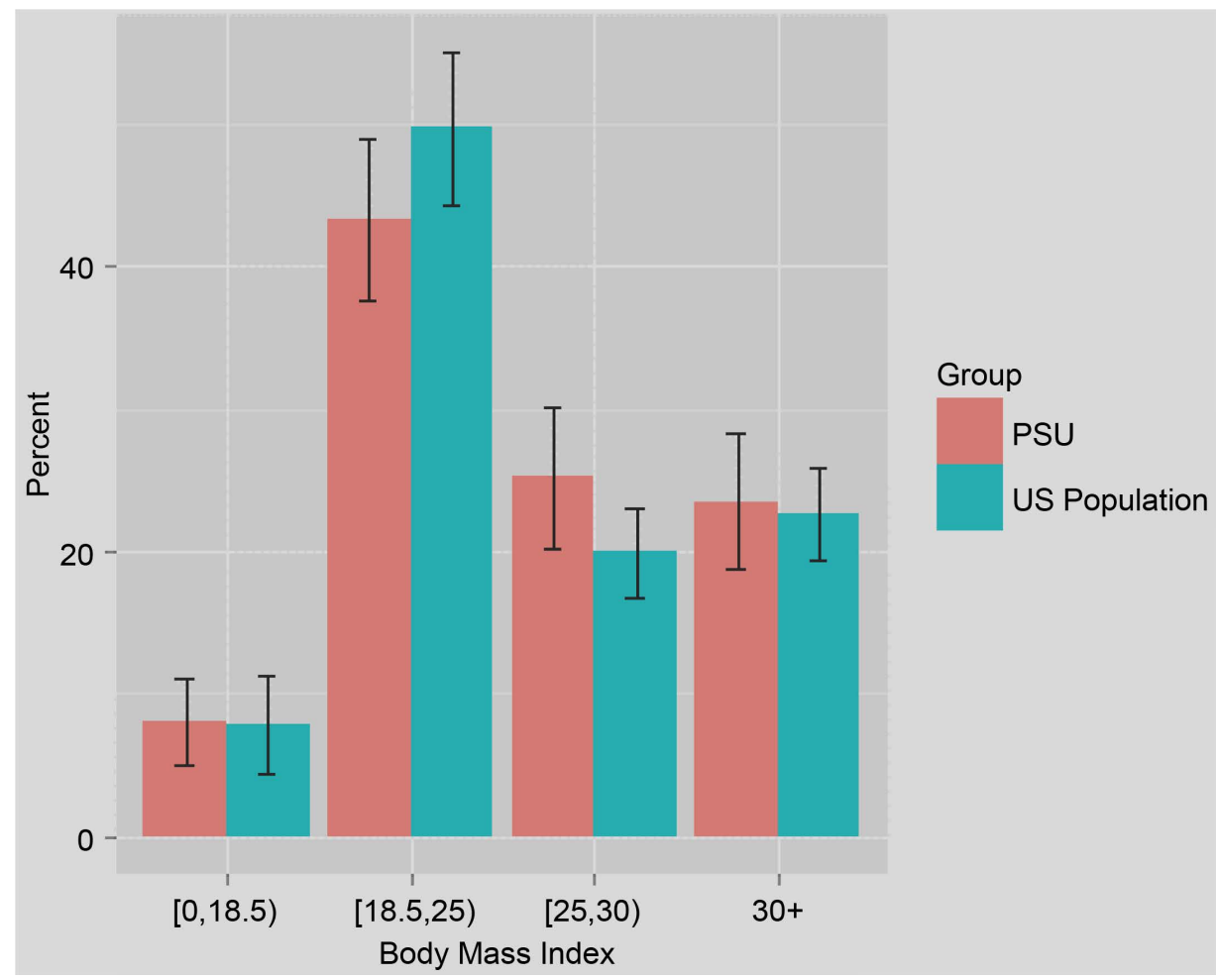

Figure 1. Proportions (with 95\% CI's) of Saudi students and their American counterparts within each categories of BMI.

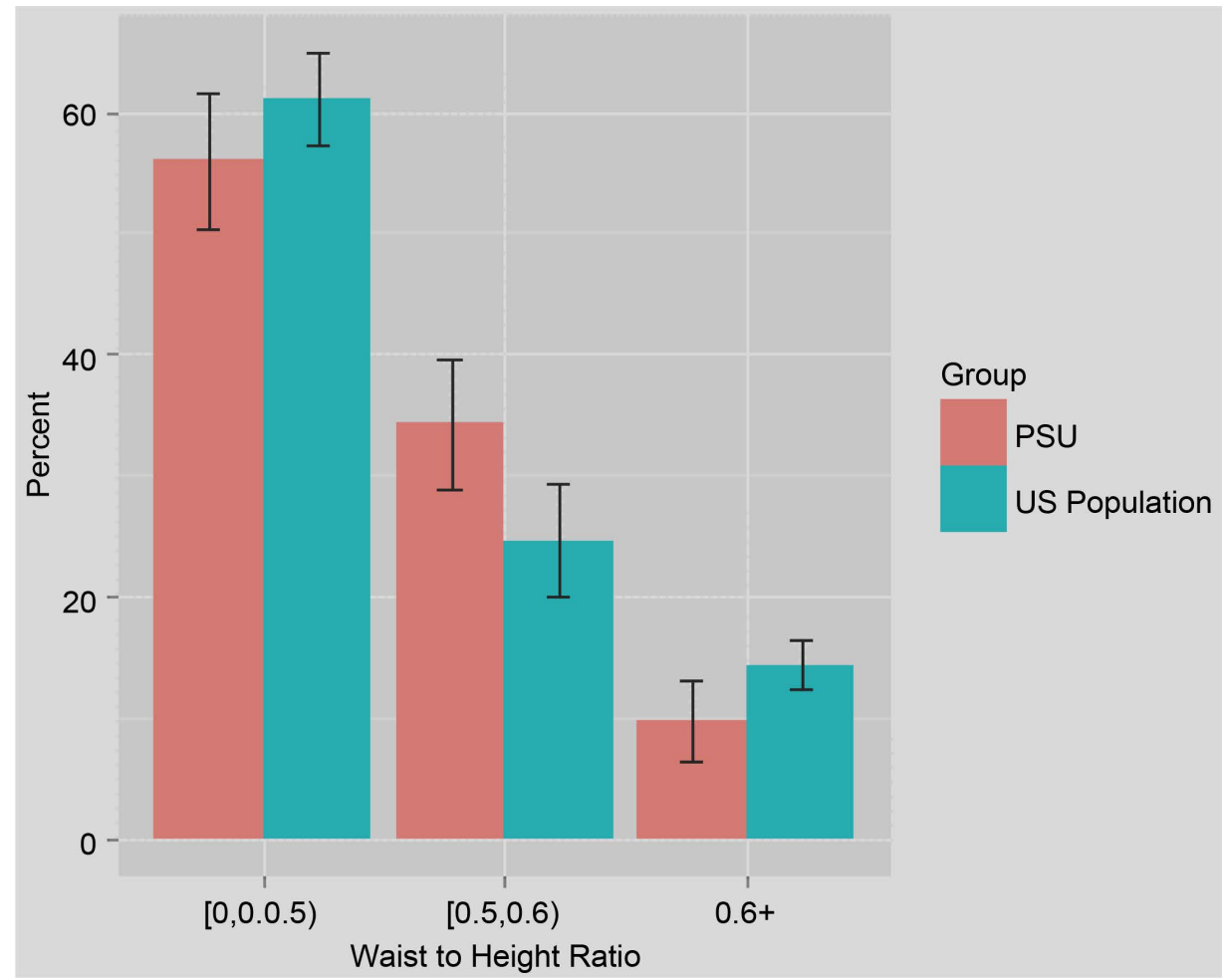

Figure 2. Proportions (with 95\% CI's) of Saudi students and their American counterparts within each categories of WHR. 
to that of in Americans of the same gender and age, should raise serious concern about the future health risks these students are exposed to ( $\mathrm{Ng}$ et al., 2014; R Core Team, 2013; Nguyen et al, 2008). Immediate effort should be put into prevention and information programs that promote exercise and healthy eating among these young students.

The random sample of Saudi students was drawn, for convenience, from one university. Although we did not include students from other universities, our random sample was taken from students majoring in different fields from humanities to business to engineering. Therefore, we can reasonably assume that our sample is representative of Saudi students from 18 to 20 years of age. Due to limitations in the available data on the American participants in the NHANES survey (there was no information on whether the participants were attending college at the time where the weight and height measurements were taken), we compared our sampled students to average Americans of the same age, instead of comparing them to American male students of the same age. That just makes our results more conservative given evidence from previous studies that found years of education to be negatively correlated with Body Mass index (Marion et al., 2011). In other words, if we can state that a Saudi male student is as likely to be obese as an average American male of the same age, then we can reasonably state a Saudi student is not likely to be less obese than a male American student of the same age.

\section{Acknowledgments}

This work is supported by the funded research project "Body Mass Index: A comparison of Saudi Students to their Americans counterparts" under the grant of the Research \& Translation Center of Prince Sultan University. The authors would like to thank Prince Sultan University for funding this work through Research Grant Number GPOYP-2013-11-24.

\section{Conflict of Interest}

All authors have no conflict of interest to report.

\section{References}

Abbasi, F., Brown, B. W., Lamendola, C., McLaughlin, T., \& Reaven, G. M. (2002). Relationship between Obesity, Insulin Resistance, and Coronary Heart Disease Risk. Journal of the American College of Cardiology, 40, 937-943. http://dx.doi.org/10.1016/S0735-1097(02)02051-X

Al-Almaie, S. M. (2005). Prevalence of Obesity among Saudi Adolescents in Eastern Saudi Arabia. Saudi Medical Journal, 26, 607-611.

Al-Nozha, M. M., Al-Mazrou, Y. Y., Al-Maatouq, M. A., Arafah, M. R., Khalil, M. Z., Khan, N. B., Al-Marzouki, K., Abdullah, M. A., Al-Khadra, A. H., Al-Harthi, S. S., Al-Shahid, M. S, AlMobeireek, A., \& Nouh, M. S. (2005). Obesity in Saudi Arabia. Saudi Medical Journal, 26, 824829.

Al-Rethaiaa, A. S., Fahmy, A. E., \& Al-Shwaiyat, N. M. (2010). Obesity and Eating Habits among College Students in Saudi Arabia: A Cross Sectional Study. Nutrition Journal, 9, 1-10. http://dx.doi.org/10.1186/1475-2891-9-39 
Al-Rukban, M. O. (2003). Obesity among Saudi Male Adolescents in Riyadh, Saudi Arabia. Saudi Medical Journal, 24, 27-33.

Alsaif, M. A., Hakim, I. A., Harris, R. B., Alduwaihy, M., Al-Rubeaan, K., Al-Nuaim, A. R., \& Al-Attas, O. S. (2002). Prevalence and Risk Factors of Obesity and Overweight in Adult Saudi Population. Nutrition Research, 22, 1243-1252.

http://dx.doi.org/10.1016/S0271-5317(02)00439-6

CDC National Center for Health Statistics (2011). National Health and Nutrition Examination Survey. http://www.cdc.gov/nchs/nhanes/nhanes questionnaires.htm

Freedland, S. J., Wen, J., Wuerstle, M., Shah, A., Lai, D., \& Moalej, B. (2008). Obesity Is a Significant Risk Factor for Prostate Cancer at the Time of Biopsy. Urology, 72, 1102-1105. http://dx.doi.org/10.1016/j.urology.2008.05.044

Grummer-Strawn, L. M., Reinold, C. M., Krebs, N.F., \& Centers for Disease Control and Prevention (CDC) (2010). Use of World Health Organization and CDC Growth Charts for Children Aged 0 - 59 Months in the United States. Morbidity and Mortality Weekly Report (MMWR), 59, 1-15.

James, W. P. T, Jackson-Leach, R., Mhurchu, C. N., Kalamara, E., Shayeghi, M., \& Rigby, N. J. (2004). Overweight and Obesity (High Body Mass Index). In M. Ezzati, A. D. Lopez, A. Rodgers, \& C. J. L. Murray (Eds.), Comparative Quantification of Health Risks: Global and Regional Burden of Disease Attributable to Selected Major Risk Factors (pp. 497-596). Geneva: World Health Organization.

Marion, D., Franco, S., Jody, Ch., Michele, C., \& Francesca, B. (2011). Exploring the Relationship between Education and Obesity. OECD Journal: Economic Studies, 2011, 1.

Ng, M., Fleming, T., Robinson, M., Thomson, B., Graetz, N., \& Margono, C. (2014). Global, Regional and National Prevalence of Overweight and Obesity in Children and Adults during 1980-2013: A Systematic Analysis for the Global Burden of Disease Study 2013. The Lancet, 384, 766-781. http://dx.doi.org/10.1016/S0140-6736(14)60460-8

Nguyen, N. T., Magno, C. P., Lane, K. T., Hinojosa, M. W., \& Lane, J. S. (2008). Association of Hypertension, Diabetes, Dyslipidemia, and Metabolic Syndrome with Obesity: Findings from the National Health and Nutrition Examination Survey, 1999 to 2004. Journal of the American College of Surgeons, 207, 928-934. http://dx.doi.org/10.1016/j.jamcollsurg.2008.08.022

R Core Team (2013). R: A Language and Environment for Statistical Computing. Vienna: $\mathrm{R}$ Foundation for Statistical Computing. http://www.R-project.org/

Submit or recommend next manuscript to SCIRP and we will provide best service for you:

Accepting pre-submission inquiries through Email, Facebook, LinkedIn, Twitter, etc.

A wide selection of journals (inclusive of 9 subjects, more than 200 journals)

Providing 24-hour high-quality service

User-friendly online submission system

Fair and swift peer-review system

Efficient typesetting and proofreading procedure

Display of the result of downloads and visits, as well as the number of cited articles

Maximum dissemination of your research work

Submit your manuscript at: http://papersubmission.scirp.org/

Or contact ape@scirp.org 